\title{
ERRATUM
}

Subal C. Kumbhakar

\section{Specification and estimation of nonstandard profit functions}

Published online: 18 May 2006

(C) Springer-Verlag 2006

\section{Empirical Economics (2006) 31:243-260}

In the original article the spelling of the author's name was incorrect. This is the right name.

The online version of the original article can be found at http://dx.doi.org/10.1007/s00181005-0043-4

S. C. Kumbhakar $(\square)$

Department of Economics, State University of New York-Binghamton,

Binghamton, NY 13902, USA

E-mail: kkar@binghamton.edu 